Estimation versus measurement of tree heights in forest inventories

\section{G. M. BONNOR}

Forest Management Institute

Canadian Forestry Service

Department of the Environment

Ottawa, Ontario
Estimation contre mensuration des hauteurs $d^{\prime}$ arbres pour les inventaires forestiers. A la suite d'un test effectué à Terre-Neuve, l'auteur préconise qu'il n'est en général pas nécessaire de mesurer la hauteur de tous les arbres dans une place-échantillon, lors d'un inventaire. On peut mesurer la hauteur d'un certain nombre d'entre eux et évaluer celle des autres. Pour déterminer le nombre ou pourcentage d'arbres à mesurer directement, l'auteur donne des conseils pertinents.
Many foresters feel that, in field surveys used to obtain inventory data, it is a waste of time to measure the heights of all trees in the sample units. They argue that with a few tree heights measured per sample unit, the remainder can be estimated with little error, and that this error will not affect volume estimates significantly.

During a recent field survey conducted by the Newfoundland Forest Service, data were collected which may help to resolve this argument. The survey was made in softwood stands of about $40 \mathrm{ft}(12 \mathrm{~m})$ in average height, with a range of 25 to $60 \mathrm{ft}$ ( 8 to $18 \mathrm{~m}$ ). Stand density averaged 500 trees/acre $(1,200$ trees/ha), with a range of 120 to 900 trees/acre (300 to 2,200 trees/ha). Sample units consisted of point samples, with an average of 10 trees selected per point.

On each of 209 sample units, the heights of all selected trees were measured.

On each of 490 additional units, a few tree heights were measured and all heights were estimated, instead of being measured. The procedure was to estimate the height of the first tree, measure it, estimate the heights of nearby trees visible from the same spot, move to another spot and repeat these steps. In total, the heights of 1,112 trees, averaging 2.3 trees per point, were both measured and estimated. These data were used to evaluate bias and variation of the tree-height estimates.

On all sample units, stem diameters were measured, species noted, and information pertaining to the stand characteristics was collected. The time required to complete each unit was also noted.

The results were as follows:

a/ the average time required to collect data for one point was 12.5 minutes when only a few trees were measured, and 17.7 minutes when all trees were measured, for an increase of 5.2 minutes or approximately $40 \%$;

b/ the bias due to height estimation was -0.06 $\mathrm{ft}(-0.02 \mathrm{~m})$ per tree;

c/ the standard deviation of differences between measured and estimated heights was \pm 1.9 ft $( \pm 0.57 \mathrm{~m})$, i.e. the estimated heights were within $1.9 \mathrm{ft}(0.57 \mathrm{~m})$ of the measured heights two times out of three.

The $40 \%$ time difference shown in a/ is quite large and, although it will be "diluted" when the time of other field sampling tasks is considered (e.g. moving from one point sample to the next), it is likely to remain significant. If estimation rather than complete measurement were employed, two additional point samples could be measured in a day.

The bias due to estimation of height is so small that it can be ignored; its influence on volume estimates is not significant.

The variation of $\pm 1.9 \mathrm{ft}( \pm 0.57 \mathrm{~m})$ may have some effect on volume estimates. To evaluate the order of magnitude of this error, four point samples were selected and the volumes per acre were calculated using $1 /$ measured heights and 2/ measured heights plus or minus a simulated error based on the standard deviation of $\pm 1.9 \mathrm{ft}( \pm 0.57 \mathrm{~m})$. For the individual points, volume differences ranged from 0.17 to $1.44 \%$, while the volume difference for the average of the four points was $0.16 \%$.

Thus, the errors due to measuring only a few tree heights on a sample unit and estimating the remainder are apparently minor and do not affect volume estimates significantly. Since the additional time required to measure all trees is significant, it would indeed seem to be a waste of time to measure them all.

This conclusion is based on results obtained from a large sample, in which over- and underestimates of heights are reasonably well balanced, i.e. the bias is small. In small samples, such a balance may not occur. Estimates for single points containing few trees, or averages based on a few points, might be significantly biased. It would therefore be prudent to keep the sample size reasonably large. The alternative would be to measure a greater proportion of trees.

The number of trees to measure in a sample unit depends on other considerations as well. In general, the taller the trees, or the larger the range of tree heights, or the denser the stand, the more trees should be measured. Further considerations are the proficiency of the field crew and the size of the sample unit.

The present results were obtained under favourable conditions: short trees, little height variation, open stands, and experienced field crews. In many situations, more trees will likely have to be measured per sample unit to avoid significant errors due to estimation. The best approach is probably to specify a minimum number of trees to be measured per sample unit, and to instruct the field crew to measure additional trees as required by stand conditions. 